\title{
Spontaneous intraorbital hematoma: case report
}

This article was published in the following Dove Press journal:

Clinical Ophthalmology

15 December 2010

Number of times this article has been viewed

\section{Vinodan Paramanathan \\ Ardalan Zolnourian}

Queen's Hospital NHS Foundation Trust, Burton on Trent, Staffordshire DEI 3 ORB, UK
Correspondence: Vinodan Paramanathan Queen's Hospital NHS Foundation Trust Burton on Trent, Staffordshire DEI 3 ORB, UK

$\mathrm{Tel}+44(0)$ I 2835 I I 5 I I

Emailvphammers@live.co.uk
Abstract: Spontaneous intraorbital hematoma is an uncommon clinical entity seen in ophthalmology practice. It is poorly represented in the literature. Current evidence attributes it to orbital trauma, neoplasm, vascular malformations, acute sinusitis, and systemic abnormalities. A 65-year-old female presented with spontaneous intraorbital hematoma manifesting as severe ocular pains, eyelid edema, proptosis, and diplopia, without a history of trauma. Computer tomography demonstrated a fairly well defined extraconal lesion with opacification of the paranasal sinuses. The principal differential based on all findings was that of a spreading sinus infection and an extraconal tumor. An unprecedented finding of a spontaneous orbital hematoma was discovered when the patient was taken to theater. We discuss the rarity of this condition and its management.

Keywords: hemorrhage, ophthalmology, spontaneous, intra-orbital, hematoma

\section{Introduction}

Current evidence attributes the formation of an intraorbital hematoma to trauma, neoplasm, acute sinusitis, and systemic vascular abnormalities. Its development without concomitant disease is an uncommon clinical entity seen in ophthalmology practice, and it is poorly represented in the literature. The patient typically presents with ocular pain, acute visual loss, and proptosis.

\section{Case presentation}

A 65-year-old female was referred by her general practitioner to Accident and Emergency with a 2-day history of severe unilateral, left-sided ocular pains and orbital swelling associated with double vision. Her symptoms had developed expeditiously. The casualty doctor reviewing the patient had documented a tender and swollen left eyelid. This was associated with a diffuse red eye and proptosis. The visual acuity in her left eye was $6 / 12$ on admission. There were no concomitant ear, nose, and throat symptoms, and she had been systemically well. Relevant past medical history included bilateral ethmoidectomies, middle meatal antrostomies, and avulsion of nasal polyps for recurrent sinusitis. She had been taking antihypertensive medication but was not on any form of anticoagulants. Blood tests revealed a mildly raised neutrophil count with no other abnormalities. The patient was admitted for observations and issued an emergency ophthalmology clinic appointment. A provisional diagnosis of orbital cellulitis was made by the reviewing physician. Initial management was treatment with intravenous antibiotics and topical steroid eye drops. The patient was reviewed in the clinic 2 days later and subsequently admitted for urgent inpatient investigations, 


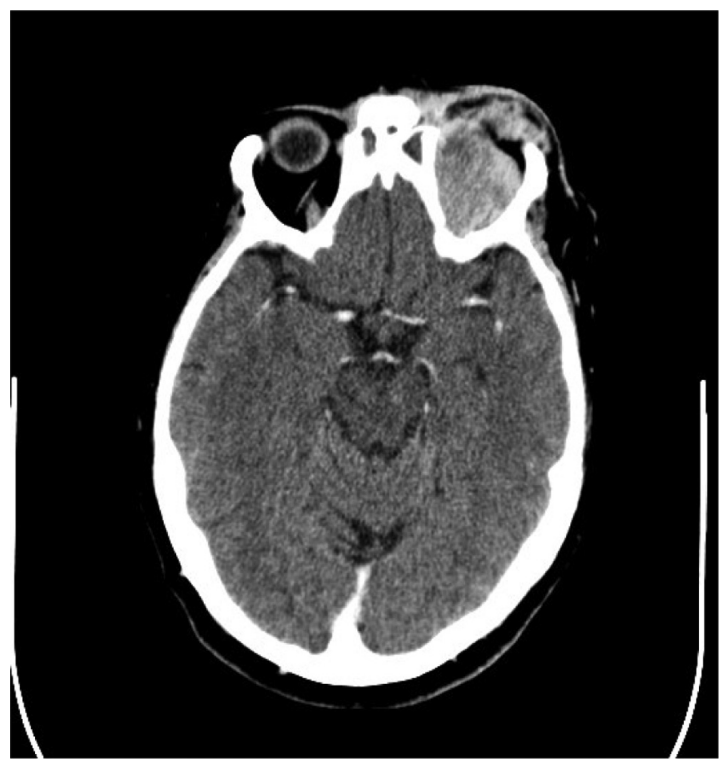

Figure I A fairly well defined lesion measuring $31 \mathrm{~mm} \times 31 \mathrm{~mm} \times 16 \mathrm{~mm}$ can be seen in the superior aspect of the extraconal space of the left orbit, pushing the superior rectus and levator palpabrae superioris inferolaterally and causing significant proptosis. Both frontal sinuses were completely opacified, including the paranasal sinuses.

as her symptoms did not improve clinically. A computed tomography scan of the head and orbits was performed (see Figures 1 and 2).

The patient was listed for a lateral orbital canthotomy to decompress the retrobulbar collection. Altered blood was evacuated during the procedure without documentation of

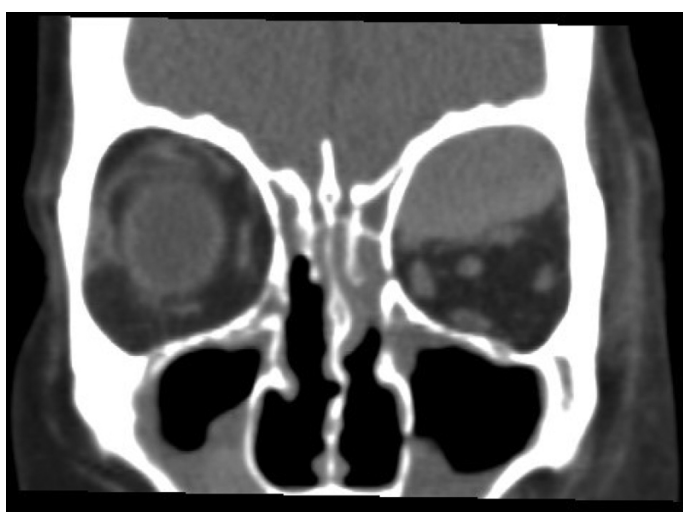

Figure 2 The rest of the extraocular muscles were unremarkable. Significant softtissue edema is seen around the orbit. The optic nerve sheath complex has a normal course with no evidence of compression on it. any other significant findings. A subsequent histopathology report revealed an organizing hematoma with accumulation of bile pigment and hematoidin. In addition, there was a low inflammatory cell count with no identifiable abnormal cells. A spontaneous intraorbital hematoma was concluded in the absence of an orbital tumor, eroding nasal polyps, or sinus infection. Three weeks following the operation, the patient made a full recovery with a return to her normal visual acuities.

\section{Discussion}

A spontaneous intraorbital hematoma was an unprecedented finding, considering that the clinical picture alluded to the chief differentials of orbital cellulitis and an extraconal tumor. Other than a history of recurrent nasal polyps, there were no clear predisposing factors to note. It is an uncommon event and has been hypothesized to be due to a sudden increase in intraorbital pressure or systemic disease. ${ }^{1}$ Acute rhinosinusitis has been reported to be the intraorbital complication in the vast majority of cases in which diplopia and proptosis are the presenting symptoms. ${ }^{2}$ Conservative management with systemic corticosteroids is considered to be ineffective; ${ }^{3}$ thus, ultimately, surgical decompression is required to restore vision or prevent further visual loss.

\section{Disclosure}

The authors report no conflicts of interest in this work.

\section{References}

1. Martinez Devesa P. Spontaneous orbital haematoma. J Laryngol Otol. 2002;116(11):960-961.

2. Brooks AMV, Finkelstein D. Spontaneous orbital haemorrhage. Br J Ophthalmol. 1984;68:838-840.

3. Kwon JH, Song YJ, Choi SS, Kim KU. Spontaneous intraorbital haemorrhage: a case report. J Korean Neurosurg Soc. 2008;44(3): $156-158$
Clinical Ophthalmology

\section{Publish your work in this journal}

Clinical Ophthalmology is an international, peer-reviewed journal covering all subspecialties within ophthalmology. Key topics include: Optometry; Visual science; Pharmacology and drug therapy in eye diseases; Basic Sciences; Primary and Secondary eye care; Patient Safety and Quality of Care Improvements. This journal is indexed on

\section{Dovepress}

PubMed Central and CAS, and is the official journal of The Society of Clinical Ophthalmology (SCO). The manuscript management system is completely online and includes a very quick and fair peer-review system, which is all easy to use. Visit http://www.dovepress.com/ testimonials.php to read real quotes from published authors. 